Jurnal Ilmu Keperawatan : Journal of Nursing Science 2020, Vol. 8, No. 1, 1-9

www.jik.ub.ac.id

Doi 10.21776/ub.jik.2020.008.01.1

P-ISSN: 2088-6012 E-ISSN: 2598-8492

Research article

\title{
DESCRIPTION OF KNOWLEDGE, ATTITUDE, AND BEHAVIORAL BREASTFEEDING ON WORKING MOTHER IN THE ARJASA COMMUNITY HEALTH CENTER WORKING AREA IN JEMBER REGENCY
}

Fitri Al Vianita ${ }^{1}$, Dini Kurniawati ${ }^{1 *}$, Peni Perdani Juliningrum ${ }^{1}$

Afiliasi

1. Faculty of Nursing, University of Jember

Dikirim 30 April 2019
Direvisi 12 Desember 2019
Diterima 30 Desember 2019
Dipublikasi 30 Juni 2020

*Korespondensi

Email :

dini_psikunej10@yahoo.com

\begin{abstract}
ABSTRAK
Pemberian ASI Ekskusif merupakan cara efektif untuk mencegah kematian anak. Salah satu faktor yang menjadi kendala dalam pemberian ASI eksklusif adalah status ibu yang bekerja dapat mempengaruhi ibu untuk memberikan ASI eksklusif, terutama jika ibu tidak memiliki pengetahuan tentang pemberian ASI eksklusif. Tujuan dari penelitian ini adalah untuk mengetahui bagaimana gambaran pengetahuan, sikap, dan perilaku pemberian ASI eksklusif pada ibu yang bekerja di Wilayah Kerja Puskesmas Arjasa di Kabupaten Jember. Jenis penelitian ini adalah deskriptif dengan pendekatan cross-sectional dan menggunakan teknik purposive sampling. Pengumpulan data dilakukan dengan menggunakan kuesioner. Analisis data dalam penelitian ini adalah analisis univariat untuk mengetahui frekuensi dan persentase masing-masing sub variabel. Hasil penelitian menunjukkan bahwa Ibu pekerja memiliki pengetahuan kurang sebanyak 3\%, pengetahuan cukup sebanyak 3\% dan pengetahuan yang baik sebanyak $61 \%$. Ibu pekerja memiliki sikap yang cukup sebanyak $16 \%$, dan sikap yang baik sebanyak 51\%. Ibu pekerja yang memberikan ASI eksklusif sebanyak 40\% dan tidak memberikan ASI eksklusif sebanyak $27 \%$ dari total responden. Pengetahuan dan sikap terhadap pemberian ASI eksklusif dapat mendukung ibu untuk memberikan ASI eksklusif. Pengetahuan dan sikap bukan hanya faktor yang mempengaruhi pemberian ASI eksklusif, di wilayah ini status pekerjaan memainkan peran yang lebih besar. Bekerja tidak dapat digunakan sebagai alasan ibu tidak memberikan ASI eksklusif. Hak dan kesejahteraan ibu telah dijamin dan dilindungi oleh Undang-Undang Kesehatan dan Ketenagakerjaan
\end{abstract}

Kata kunci : ASI ekslusif, pengetahuan, sikap, perilaku, ibu pekerja

\begin{abstract}
Exclusive breastfeeding is an effective way to prevent child mortality. One of the factors that become an obstacle in exclusive breastfeeding is the status of the mother who works, which affects the mother to give exclusive breastfeeding, especially if the mother doesn't know about exclusive breastfeeding. The purpose of this study was to find out how the description of knowledge, attitudes, and behavior of exclusive breastfeeding on working mothers in the Arjasa Community Health Center Working Area in Jember Regency. This type of research is descriptive with a cross-sectional approach and use a purposive sampling technique. Data collection was finished using a questionnaire. Univariate analysis was used to determine the frequency and percentage of each subvariable. The results showed that 3\% of working mothers have less knowledge, 3\% have enough knowledge, and 61\% have good knowledge. 16\% of working mothers have enough attitude, 51\% have a good attitude. Working mothers who gave exclusive breastfeeding as much as $40 \%$ and did not give exclusive breastfeeding as much as $27 \%$ of the total of respondents. Knowledge and attitudes towards exclusive breastfeeding can support mothers to give exclusive breastfeeding. Knowledge and attitude are not the only factors that influence exclusive breastfeeding, in this region the status of the work plays a greater role. Works can not be used as an excuse for the mother not to give exclusive breastfeeding. The rights and welfare of the mother have been guaranteed and protected by the Health Law and Labor Law.
\end{abstract}

Keyword : exclusive breastfeeding, knowledge, attitude, behavioral, working Mothers

Sitasi jurnal :

Al Vianita F, Kurniawati D, Juliningrum PP. 2020. Description Of Knowledge, Attitude, And Behavioral Breastfeeding On Working Mother In The Arjasa Community Health Center Working Area In Jember Regency. Jurnal Ilmu Keperawatan Volume 8 (1): 1-9 Doi 10.21776/ub.jik.2020.008.01.1 


\section{PENDAHULUAN}

ASI eksklusif merupakan langkah yang efektif untuk mencegah kematian anak. Berdasarkan Riset Kesehatan Dasar tahun 2013, persentase pemberian ASI eksklusif untuk bayi berusia 0-1 bulan adalah 48,2 $\%$, usia 2-3 bulan menurun menjadi $42,2 \%$, menurun kembali di usia 4-5 bulan 36,6\% dan 30,2\% pada usia 6 bulan. Angka tersebut masih jauh dari target cakupan ASI nasional sebesar 80\%. Angka ini dipengaruhi oleh beberapa faktor.

Faktor penghambat pemberian ASI adalah keluarnya ASI yang sedikit, ibu bekerja sehingga tidak ada waktu dalam pemberian ASI, kekhawatiran ibu menjadi gemuk, terjadinya diare saat diberi ASI, bayi yang terlihat kurang gemuk ketika diberi ASI sedangkan saat diberi susu formula terlihat gemuk, kurangnya informasi mengenai ASI Eksklusif, pengaruh orang terdekat seperti suami, dan adanya kebiasaan masyarakat yang masih memberikan makanan pendamping sepeeti pisang, nasi halus, dan bubur pada bayi (Riksani, 2012). Hasil penelitian menunjukkan bahwa faktor paling dominan berhubungan dengan pemberian ASI eksklusif adalah pengetahuan ibu. Ibu dengan pengetahuan yang baik memiliki peluang untuk bisa memberikan ASI Eksklusif sebesar 13 kali lebih besar dibandingkan ibu yang memiliki pengetahuan kurang (Septiani dkk, 2017).

Beberapa kebijakan ditetapkan oleh Pemerintah dalam meningkatkan cakupan pemberian ASI eksklusif di Indonesia. Peraturan Pemerintah Nomor 33 Tahun 2012 menginstruksikan kepada pemerintah daerah dan swasta untuk bekerjasama mendukung pemberian ASI eksklusif dan Inisiasi Menyusui Dini (IMD). Melalui Peraturan Pemerintah ini, pemerintah memformalkan hak perempuan untuk menyusui (termasuk di tempat kerja) dan melarang promosi pengganti ASI. Pemberian ASI eksklusif dan IMD bertujuan untuk memenuhi kebutuhan nutrisi bayi dan mencegah kekurangan gizi pada balita (Kemenkes, 2013).

ASI perah dapat menjadi solusi bagi ibu pekerja untuk tetap memenuhi kebutuhan ASI eksklusif untuk bayi. Dari ibu yang memberikan ASI eksklusif, sekitar 70,7\% responden meninggalkan bayi kurang dari 10 jam saat bekerja sedangkan 58,2\% responden meninggalkan bayi lebih dari 10 jam (Abdullah \& Ayubi, 2010).
Puskesmas Arjasa termasuk salah satu dari 50 puskesmas yang ada di Kabupaten Jember. Berdasarkan data Dinas Kesehatan Kabupaten Jember 2017 di Puskesmas Arjasa terdapat 187 bayi yang diberi ASI Eksklusif dengan persentase cakupan ASI Eksklusif sebanyak 32,12\% ini berarti terjadi kesenjangan sebanyak 47,88\% dari target cakupan ASI Eksklusif sebanyak 80\%. Wilayah Kerja Puskesmas Arjasa termasuk wilayah yang memiliki cakupan ASI yang rendah bersama dengan Puskesmas Kasiyan sebanyak 19,93\%, Puskesmas Rowotengah sebanyak 25,00\%, Puskesmas Cakru 26,6\%, dan Puskesmas Tanggul sebanyak 28,99\%. Puskesmas Arjasa memiliki wilayah kerja yang merupakan kawasan industri dan pertanian. Terdapat 510 Industri yang ada di Kecamatan Arjasa dengan tenaga kerja sebanyak 3.501 orang. (BPS Kabupaten Jember, 2018).

Karena itu, peneliti bermaksud untuk meneliti gambaran pengetahuan, sikap, dan perilaku pemberian ASI Eksklusi pada ibu pekerja di wilayah kerja Puskesmas Arjasa Kabupaten Jember.

\section{METODE}

Penelitian ini termasuk dalam jenis penelitian kuantitatif desain penelitian studi deksriptif dengan pendekatan cross sectional. Populasi dalam penelitian ini adalah ibu yang memiliki bayi berusia 6-12 bulan di Wilayah Kerja Puskesmas Arjasa. Teknik sampling menggunakan teknik purposive sampling yaitu dengan jumlah sampel 70 responden dengan kriteria inklusi yaitu ibu dari bayi berusia 6-12 bulan di Wilayah Kerja Puskesmas Arjasa serta bersedia menjadi responden dan dengan kriteria eksklusi responden tidak secara sukarela berpartisipasi dalam penelitian.

Peneliti menentukan responden berdasarkan kriteria inklusi dan ekslusi yang peneliti tetapkan. Peneliti menjelaskan kepada pasien mengenai maksud, tujuan dan prosedur penelitian. Penelitian ini telah mendapatkan izin etik penelitian dari KEPK Fakultas Kedokteran Gigi Universitas Jember dengan nomor surat 279/UN25.8/KEPK/DL/2019.

Penelitian ini menggunakan kuesioner sebagai alat pengumpul data. Kuesioner merupakan teknik pengumpulan data dengan cara memberi lembar 
berisi seperangkat pertanyaan kepada responden untuk dijawab. (Notoatmodjo, 2012). Alat pengumpul data terdiri atas 4 bagian, yaitu formulir A berisi tentang karakteristik responden, formulir B tentang pengetahuan ASI eksklusif, formulir C berisi tentang sikap terhadap ASI eksklusif, dan formulir D berisi tentang perilaku pemberian ASI eksklusif. Kuisioner dibuat dengan bersumber dari penelitian yang dilakukan Rahman N, dkk (2017).

\section{HASIL}

Hasil penelitian ditampilkan dalam bentuk narasi dan tabel. Data dibagi menjadi data umum dan data khusus. Data umum berisi tentang hasil analisis univariat dari karakteristik sampel penelitian yaitu Usia, pendidikan terakhir, pekerjaan, dan lama bekerja dalam sehari. Data khusus terdiri dari variabel penelitian yaitu pengetahuan, sikap, dan perilaku pemberian ASI ekslusif.

\section{Karakteristik Sampel Penelitian}

Sebagian besar responden dalam penelitian ini berusia 20-35 tahun (79\%). Pendidikan terakhir responden paling banyak pada SMP sederajat sebanyak 24 orang (34\%), Pekerjaan terbanyak adalah ibu rumah tangga sebanyak 23 orang (33\%) dan karyawan pabrik 19 orang (27\%) dan lama bekerja sehari adalah 9-12 jam sebanyak 19 orang (41\%) (Tabel 1).

Tabel 1. Distribusi frekuensi karakteristik responden

\begin{tabular}{clrc}
\hline No & $\begin{array}{l}\text { Karakteristik } \\
\text { Responden }\end{array}$ & $\begin{array}{c}\text { f } \\
\text { (orang) }\end{array}$ & $\begin{array}{c}\text { Persentase } \\
\text { (\%) }\end{array}$ \\
\hline $\mathbf{1}$ & Usia Ibu & & \\
& a. Dibawah 20 tahun & 6 & 8 \\
& b. 20-35 tahun & 55 & 79 \\
& c. Diatas 35 tahun & 9 & 13 \\
\hline \multicolumn{2}{l}{ Total } & $\mathbf{7 0}$ & $\mathbf{1 0 0}$ \\
\hline $\mathbf{2}$ & Pendidikan Terakhir & & \\
& a. Tidak tamat SD & 1 & 2 \\
& b. SD & 22 & 31 \\
& c. SMP sederajat & 24 & 34 \\
& d. SMA sederajat & 18 & 26 \\
& e. Perguruan Tinggi & 5 & 7 \\
\hline & Total & $\mathbf{7 0}$ & $\mathbf{1 0 0}$ \\
\hline
\end{tabular}

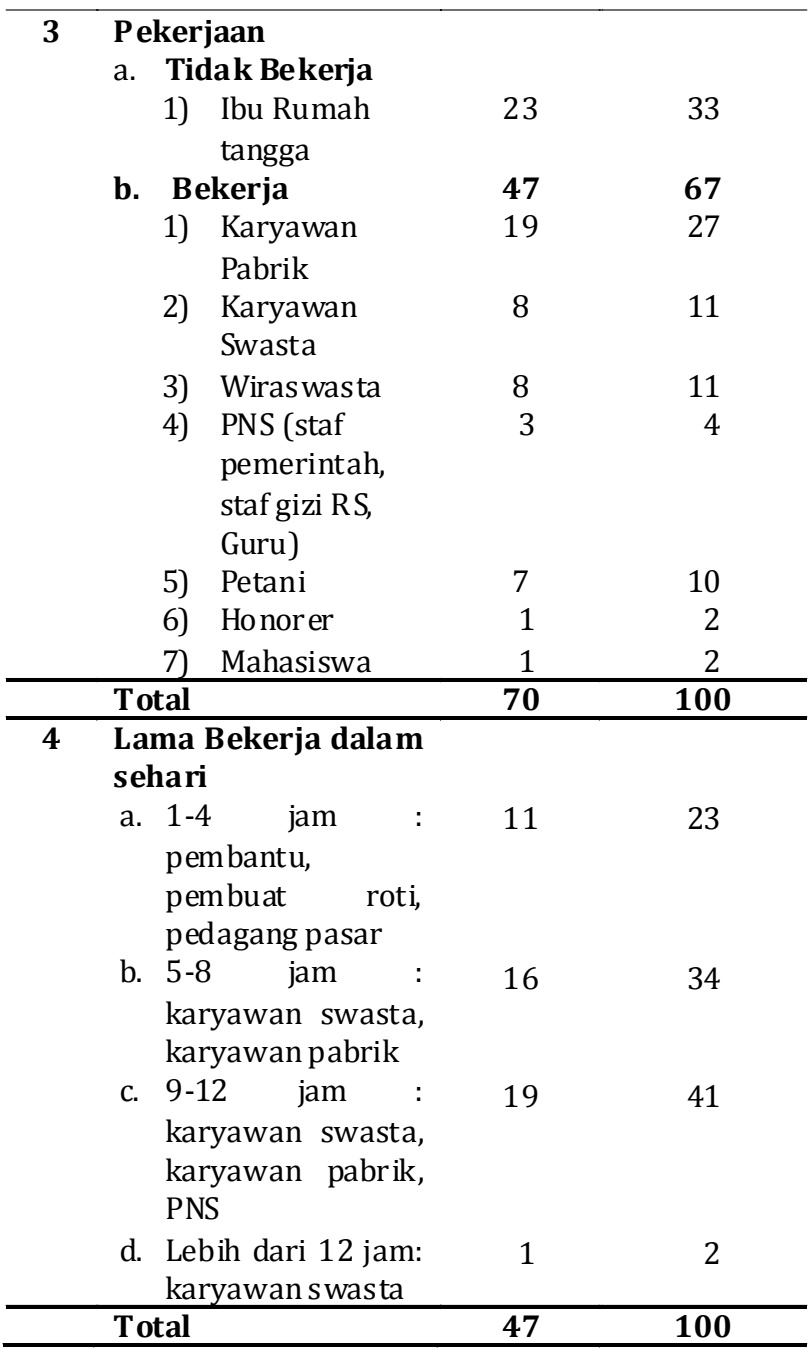

Sumber: data primer

Dari 47 ibu yang memberikan ASI ekslusif, 19 orang (27\%) berasal dari Ibu Rumah Tangga dan 28 orang (40\%) berasal dari Ibu Pekerja. 23 Ibu yang tidak memberikan ASI eksklusif, 4 orang (6\%) berasal dari ibu rumah tangga, dan 19 orang (27\%) berasal dari Ibu Pekerja (Tabel 2).

Tabel 2. Distribusi frekuensi responden menurut pemberian ASI ekslusif

\begin{tabular}{lcccccc}
\hline \multirow{2}{*}{ Pekerjaan } & \multicolumn{9}{c}{ Pemberian ASI Eksl usif } & \multirow{2}{*}{ Total } & \% \\
\cline { 2 - 5 } & Ya & $\mathbf{\%}$ & Tdk & $\mathbf{\%}$ & & \\
\hline $\begin{array}{l}\text { Ibu Rumah } \\
\text { Tangga }\end{array}$ & 19 & 27 & 4 & 6 & 23 & 33 \\
$\begin{array}{l}\text { B ekerja } \\
\text { Total }\end{array}$ & $\mathbf{4 7}$ & $\mathbf{6 7}$ & $\mathbf{2 3}$ & $\mathbf{3 3}$ & $\mathbf{7 0}$ & $\mathbf{1 0 0}$ \\
\hline
\end{tabular}

Sumber: data primer 
Tabel 3. Distribusi karakteristik responden ibu pekerja terhadap pemberian ASI ekslusif

\begin{tabular}{clcccc}
\hline \multirow{2}{*}{ No } & \multirow{2}{*}{ Karakteristik } & \multicolumn{5}{c}{ Pemberian ASI Ekslusif } \\
\cline { 3 - 6 } & Ya & \% & Tdk & \% \\
\hline 1 & Usia & & & & \\
& $\begin{array}{l}\text { a. } \quad \begin{array}{l}\text { Dibawah } 20 \\
\text { tahun }\end{array} \\
\end{array}$ & 0 & 0 & 2 & 11 \\
& b. $\quad 20-35$ tahun & 22 & 79 & 16 & 84 \\
& c. Diatas 35 & 6 & 21 & 1 & 5 \\
& $\quad$ tahun & & & & \\
\hline & Total & $\mathbf{2 8}$ & $\mathbf{1 0 0}$ & $\mathbf{1 9}$ & $\mathbf{1 0 0}$ \\
\hline 2 & Pendidikan & & & &
\end{tabular}

\begin{tabular}{|c|c|c|c|c|c|}
\hline \multirow[t]{7}{*}{$Z$} & \multicolumn{5}{|l|}{ Pendidikan } \\
\hline & a. Tidak tamat & 1 & 4 & 0 & 0 \\
\hline & SD & & & & \\
\hline & b. SD & 10 & 36 & 7 & 42 \\
\hline & c. SMP & 9 & 32 & 4 & 32 \\
\hline & d. SMA & 6 & 21 & 5 & 46 \\
\hline & $\begin{array}{l}\text { e. Perguruan } \\
\text { Tinggi }\end{array}$ & 2 & 7 & 3 & 60 \\
\hline & Total & 28 & 100 & 19 & 100 \\
\hline \multirow[t]{9}{*}{3} & \multicolumn{5}{|l|}{ Pekerjaan } \\
\hline & $\begin{array}{l}\text { a. Karyawan } \\
\text { Pabrik }\end{array}$ & 10 & 36 & 9 & 47 \\
\hline & b. Wiraswasta & 5 & 18 & 3 & 16 \\
\hline & $\begin{array}{l}\text { C. Karyawan } \\
\text { Swasta }\end{array}$ & 5 & 18 & 3 & 16 \\
\hline & d. PNS & 2 & 7 & 1 & 5 \\
\hline & e. Mahasiswa & 1 & 4 & 0 & 0 \\
\hline & f. Petani & 5 & 17 & 2 & 11 \\
\hline & g. Honorer & 0 & 0 & 1 & 5 \\
\hline & Total & 28 & 100 & 19 & 100 \\
\hline \multirow[t]{5}{*}{4} & \multicolumn{5}{|c|}{ Lama Bekerja dalam Sehari } \\
\hline & a. 1-4 jam & 9 & 32 & 2 & 11 \\
\hline & b. $5-8 \mathrm{jam}$ & 7 & 25 & 9 & 47 \\
\hline & c. 9-12 jam & 12 & 43 & 7 & 37 \\
\hline & $\begin{array}{l}\text { d. Lebih dari } \\
12 \text { jam }\end{array}$ & 0 & 0 & 1 & 5 \\
\hline & Total & 28 & 100 & 19 & 100 \\
\hline
\end{tabular}

Sumber: data primer

Tabel 4 menunjukkan bahwa sebagian besar ibu pekerja yang memberikan ASI eksklusif dengan rincian berada pada rentang usia 20-35 tahun sebanyak 22 responden (79\%), tingkat pendidikan terbanyak adalah SD sebanyak 10 responden (36\%), pekerjaan terbanyak adalah sebagai karyawan sebanyak 10 orang (36\%), dan lama bekerja dalam satu hari sebanyak 12 orang (43\%).
Tabel 4. Distribusi frekuensi pengetahuan ibu terhadap pemberian ASI eksklusif

\begin{tabular}{lcccccc}
\hline \multirow{2}{*}{ Pekerjaan } & \multicolumn{6}{c}{ Pengetahuan } \\
\cline { 2 - 7 } & \multicolumn{2}{c}{ Kurang } & \multicolumn{2}{c}{ Cukup } & \multicolumn{2}{c}{ Baik } \\
\cline { 2 - 7 } & f & \% & f & \% & f & \% \\
\hline $\begin{array}{l}\text { Ibu rumah } \\
\text { tangga }\end{array}$ & 0 & 0 & 4 & 6 & 19 & 27 \\
Bekerja & 2 & 3 & 2 & 3 & 43 & 61 \\
\hline Total & 2 & 3 & 6 & 9 & 62 & 88 \\
\hline
\end{tabular}

Sumber: data primer

Tabel 4 mengungkapkan bahwa dari 70 responden, sebanyak 19 orang (27\%) yang berasal dari ibu rumah tangga termasuk kategori pengetahuan baik, dan sebanyak 43 orang (61\%) termasuk kategori pengetahuan baik berasal dari ibu pekerja.

Tabel 5. Distribusi frekuensi sikap ibu terhadap pemberian ASI eksklusif

\begin{tabular}{lcccccc}
\hline \multirow{3}{*}{ Pekerjaan } & \multicolumn{7}{c}{ Sikap } \\
\cline { 2 - 7 } & \multicolumn{1}{c}{ Kurang } & \multicolumn{2}{c}{ Cukup } & \multicolumn{2}{c}{ Baik } \\
\cline { 2 - 7 } & f & \% & f & \% & f & \% \\
\hline $\begin{array}{l}\text { Ibu rumah } \\
\text { tangga }\end{array}$ & 0 & 0 & 0 & 0 & 23 & 33 \\
Bekerja & 0 & 0 & 11 & 16 & 36 & 51 \\
\hline Total & $\mathbf{0}$ & $\mathbf{0}$ & $\mathbf{1 1}$ & $\mathbf{1 6}$ & $\mathbf{5 9}$ & $\mathbf{8 4}$ \\
\hline
\end{tabular}

Sumber: data primer

Berdasarkan Tabel 5 mengungkapkan bahwa dari 70 responden, 23 orang (33\%) yang berasal dari ibu rumah tangga termasuk kategori sikap baik, dan dari 47 orang ibu pekerja, 11 orang (16\%) termasuk kategori sikap cukup, dan 36 orang (51\%) termasuk kategori sikap baik.

Tabel 6. Distribusi pengetahuan terhadap perilaku pemberian ASI eksklusif ibu pekerja

\begin{tabular}{lrrrr}
\hline \multirow{2}{*}{ Pengetahuan } & \multicolumn{5}{c}{ Pemberian ASI Eksklusif } \\
\cline { 2 - 5 } & Ya & $\mathbf{\%}$ & Tidak & $\mathbf{\%}$ \\
\hline Kurang & 0 & 0 & 2 & 4 \\
\hline Cukup & 1 & 2 & 1 & 2 \\
\hline Baik & 27 & 58 & 16 & 34 \\
\hline Total & $\mathbf{2 8}$ & $\mathbf{6 0}$ & $\mathbf{1 9}$ & $\mathbf{4 0}$ \\
\hline
\end{tabular}

Sumber: data primer

Tabel 6 mengungkapkan bahwa dari 47 ibu pekerja, responden yang termasuk kategori pengetahuan kurang dan tidak memberikan ASI ekslusif sebanyak 2 orang (4\%). Sedangkan responden dengan 
pengetahuan cukup dan memberikan ASI eksklusif sebanyak 1 orang (2\%) dan tidak memberikan ASI eksklusif sebanyak 1 orang (2\%). Responden yang termasuk kategori pengetahuan baik dan memberikan ASI ekslusif sebanyak 27 orang (58\%) dan tidak dapat memberikan ASI eksklusif sebanyak 16 orang (34\%).

Tabel 7. Distribusi sikap terhadap pemberian ASI eksklusif ibu pekerja

\begin{tabular}{lcccc}
\hline \multirow{2}{*}{ Sikap } & \multicolumn{4}{c}{ Pemberian ASI Ekslusif } \\
\cline { 2 - 5 } & Ya & \% & Tidak & \% \\
\hline Kurang & 0 & 0 & 0 & 0 \\
Cukup & 4 & 9 & 4 & 9 \\
Baik & 24 & 51 & 15 & 31 \\
\hline Total & $\mathbf{2 8}$ & $\mathbf{6 0}$ & $\mathbf{1 9}$ & $\mathbf{4 0}$ \\
\hline
\end{tabular}

Sumber: data primer

Berdasarkan tabel 7 menjelaskan bahwa dari 47 responden, ibu pekerja yang termasuk kategori pengetahuan cukup serta dapat memberikan ASI eksklusif sebanyak 4 orang (9\%) dan yang tidak dapat memberikan ASI ekslusif sebanyak 4 orang (9\%). Ibu yang termasuk kategori pengetahuan baik serta dapat memberikan ASI ekslusif sebanyak 24 orang (51\%) dan tidak dapat memberikan ASI Eksklusif sebanyak 15 orang $(31 \%)$.

\section{PEMBAHASAN}

Karakteristik Ibu yang memiliki bayi berusia 6-12 bulan di Wilayah Kerja Puskesmas Arjasa

Distribusi karakteristik ibu menurut usia yaitu paling banyak ibu berusia 20-35 tahun dikarenakan usia tersebut merupakan usia reproduktif dimana pada usia ini merupakan masa reproduktif. Faktor usia dapat berpengaruh dalam perubahan sikap. Semakin bertambahnya umur dapat mempengaruhi seseorang dalam pembentukan dan perubahan sikap. Cara pembentukan sikap karena sudah adanya pengetahuan, pengalaman dan bertambahnya usia disebut diferensiasi. (Sunaryo, 2004; Hargi, 2013). Hal ini sejalan dengan penelitian oleh Ramayani, dkk (2016) bahwa ibu menyusui paling banyak berada pada rentang usia 20-35 tahun. Pada rentang usia 20-35 tahun seseorang diharapkan telah mampu menghadapi masalah secara tenang, terutama kehamilan, persalinan dan merawat bayi. Ramayani, dkk (2016) mengatakan bahwa kelompok usia 20-35 memiliki kemampuan organ payudara yang matang untuk memproduksi ASI. Umur kurang dari 20 tahun dikatakan masih belum matang secara fisik dan mental dalam menghadapi kehamilan, persalinan dan pemberian ASI, sedangkan pada ibu berusia lebih dari 35 tahun dianggap berbahaya karena kemampuan fisik ibu dan alat reproduksi ibu semakin menurun, sehingga kemampuan ibu untuk menyusui tidak optimal.

Berdasarkan tingkat pendidikan, ibu yang menempuh pendidikan terakhir SMP paling banyak. Hal ini dikarenakan kesadaran untuk menempuh pendidikan lebih tinggi pada ibu di Arjasa kurang. Alasan paling umum yaitu keadaan ekonomi yang menyebabkan ibu setelah menempuh pendidikan SD dan SMP langsung menikah dan bekerja. Pendidikan yang baik memengaruhi ibu dalam memahami informasi dari berbagai sumber, misalnya dari buku, majalah, media elektronik, petugas kesehatan, serta orang-orang disekitar lingkungan ibu. Adanya informasi tentang ASI ekslusif yang diperoleh ibu baik yang diperoleh ibu secara pribadi dan didukung oleh informasi yang diperoleh ketika melakukan kegiatan posyandu membantu mereka dalam mengetahui dan memahami tentang pengetahuan ASI ekslusif yang baik dan benar (Sulistyawati dkk, 2016).

Penelitian yang dilakukan di Wilayah Kerja Puskesmas Arjasa menunjukkan bahwa ibu yang bekerja lebih banyak dari ibu yang tidak bekerja. Pekerjaan paling banyak yaitu sebagai karyawan pabrik karena wilayah Arjasa merupakan salah satu wilayah yang memiliki industri besar sehingga masyarakat sekitar banyak yang bekerja sebagai karyawan. Lama Bekerja ibu paling banyak dalam satu hari yaitu selama 9-12 jam yang menyebabkan ibu tidak dapat menemui bayinya selama itu dan memilih menitipkan bayinya kepada nenek, saudara, atau pengasuhnya. Menurut Abdullah (2012), ibu yang meninggalkan bayinya lebih dari 8 jam berpotensi tidak dapat memberikan ASI eksklusif.

\section{Pengetahuan mengenai ASI Ekslusif}

Hasil penelitian menunjukkan bahwa sebagian besar responden termasuk kategori berpengetahuan baik, baik ibu yang tidak bekerja dan bekerja. Pengetahuan mengenai ASI berupa apa saja yang telah diketahui oleh responden. Pengetahuan mengenai 
ASI dapat diperoleh melalui pendidikan, penyuluhan, maupun informasi melalui media massa. Hasil penelitian menunjukkan sebagian besar ibu yang bekerja memiliki pengetahuan yang baik. Dari ibu yang termasuk kategori pengetahuan baik sebanyak lebih dari setengah memberikan ASI eksklusif. Pengetahuan ini diperoleh ibu dari penyuluhan yang diadakan saat posyandu oleh Bidan Wilayah. Salah satu materi penyuluhan yaitu tentang ASI Eksklusif berisi penyampaian informasi mengenai ASI Eksklusif dan Manajemen Laktasi. Selain dari penyuluhan, ibu juga mendapat informasi dari berbagai sumber, misalnya majalah, media elektronik, dan orang-orang sekitar lingkungan ibu tinggal. Adanya informasi tentang ASI ekslusif yang didapat ibu membantu mereka dalam mengetahui serta memahami pengetahuan ASI ekslusif sehingga pengetahuan ASI ekslusif pada ibu di wilayah Arjasa ini termasuk kategori baik.

Pengetahuan ibu tentang ASI ekslusif adalah pengetahuan tentang ASI merupakan makanan paling sempurna bagi bayi dan pemberian ASI tanpa makanan serta minuman tambahan untuk bayi sampai bayi berumur 6 bulan. ASI yang keluar pada hari pertama sampai ketiga yang berwarna kekuningan disebut kolostrum, dan ASI yang keluar setelah kolostrum disebutASI transisi. ASI inibermanfaatuntukbayidalam meningkatkan daya tahan tubuh bayi, pertumbuhan otak, meningkatkan daya penglihatan dan kepandaian berbicara, dan sebagai pencegah agar bayi tidak mudah sakit. Manfaat pemberian ASI bagi ibu adalah dapat meningkatkan jalinan kasih sayang, sebagai metode alat kontrasepsi menjarangkan kehamilan, mengurangi resiko kanker rahim serta kanker payudara. Bagi ibu, cara memperbanyak ASI adalah disusui sesering mungkin pada bayi, serta mengkonsumsi asupan makanan bergizi dan mengandung banyak cairan. ASI dapat langsung diberikan pada bayi tanpa melalui proses memasak.

Dari hasil ini didapatkan bahwa ibu yang berprofesi sebagai ibu rumah tangga dan ibu pekerja memiliki pengetahuan yang baik. Hal ini membuktikan bahwa program penyuluhan tentang ASI ekslusif pada wilayah kerja Puskesmas Arjasa berjalan dengan baik dalam hal pemberian informasi. Pengetahuan yang baik terhadap ASI ekslusif dapat memengaruhi ibu pekerja untuk tetap memberikan ASI eksklusif. Hasil penelitian ini sesuai dengan penelitian Ilhami
(2015) yang menyatakan bahwa persentase ibu yang memberikan ASI eksklusif dan memiliki pengetahuan tentang ASI ekslusif lebih besar daripada responden yang memberikan ASI eksklusif dan memiliki pengetahuan kurang. Demikian pula dengan penelitian yang dilakukan Mekuria dan Edris, (2015) bahwa ibu dengan pengetahuan baik berpeluang 2,6 kali lebih mungkin untuk memberikan ASI eksklusif.

Hasil penelitian ini tidak sejalan dengan penelitian oleh Abdullah (2012) bahwa tingginya tingkat pengetahuan tidak selalu diiringi dengan perilaku yang positif. Kecenderungan tindakan pada kondisi pengetahuan yang baik adalah mendekati, menyenangi, mengharapkan obyek tertentu, sedangkan kecenderungan tindakan pada pengetahuan yang kurang adalah menjauhi, menghindari, membenci, tidak menyukai obyek tertentu (Azwar, 2011 dalam Firmansyah dan Mahmudah, 2014).

\section{Sikap mengenai ASI Eksklusif}

Hasil penelitian menunjukkan bahwa ibu rumah tangga menunjukkan sikap yang baik terhadap pemberian ASI eksklusif, sehingga berdampak terhadap keinginan ibu memberikan ASI ekslusif. Salah satu faktor yang dapat mendukung sikap baik dalam pemberian ASI ekslusif adalah dukungan suami. Penelitian Hargi (2013) menunjukkan bahwa pada wilayah kerja Puskesmas Arjasa semakin besar dukungan suami, maka sikap ibu dalam pemberian ASI eksklusif akan semakin positif.

Hasil penelitian pada Ibu pekerja menunjukan bahwa sebagian besar responden memiliki sikap yang baik pula terhadap pemberian ASI ekslusif. Dari hasil tersebut didapatkan bahwa ibu bekerja memiliki sikap yang baik terhadap pemberian ASI eksklusif lebih banyak dibanding dengan yang memiliki sikap cukup. Dari ibu yang bekerja, lebih dari setengah yang memiliki sikap baik yang memberikan ASI eksklusif. Semakin baik (positif) sikap ibu bekerja maka ibu semakin memberikan ASI eksklusif sebaliknya semakin kurang (negatif) sikap ibu bekerja maka ibu tidak akan memberikan ASI eksklusif pada bayi (Sulistiyowati dan Pulung, 2014). Hal ini sejalan dengan penelitian Septiani, dkk (2017) bahwa hubungan antara sikap dengan pemberian ASI Eksklusif, di mana sikap positif berpeluang 3,7 kali untuk memberikan ASI eksklusif dibandingkan dengan responden yang memiliki sikap negatif. 
Sikap adalah respon tertutup seseorang terhadap objek. Sikap pada pemberian ASI eksklusif adalah ibu harus membersihkan payudaranya dan mencuci tangan sebelum menyusui. Ibu lebih mementingkan pekerjaan daripada memberikan ASI ekslusif serta ibu menyetujui bahwa pada tempat ibu bekerja harus terdapat pojok laktasi. Kegiatan ibu bukanlah penghambat ibu untuk tetap memberikan ASI eksklusif. Ibu harus memberikan kolostrum pada bayi dari hari pertama, ibu harus segera menyusui ketika bayi lapar, dan ibu tetap memberikan ASI walaupun malam hari ketika ibu lelah bekerja. Pemberian ASI memerlukan keahlian khusus dan benar dalam menyusui dan ibu memberikan ASI tidak hanya sampai bayi berusia 6 bulan tetapi dapat dilanjutkan sampai bayi berusia 2 tahun. Saat ibu bekerja, susu formula tidak dapat menggantikan ASI karena kandungan ASI lebih lengkap daripada susu formula.

Sikap dapat ditentukan daari pengetahuan, berpikir, keyakinan, dan emosi (Notoadmodjo, 2007). Sebagian responden di wilayah kerja Puskesmas Arjasa memilih memberikan ASI ekslusif dikarenakan lebih murah dari segi ekonomi, lebih praktis dan lebih sehat untuk bayi. Persepsi ibu tentang pemberian susu formula adalah harga susu formula yang mahal tidak sebanding dengan pendapatan keluarga, dan persiapan yang harus dilakukan sebelum memberikan susu lebih lama daripada langsung memberikan ASI. Faktor yang mendorong ibu untuk menyusui adalah ajakan dan dukungan dari orang-orang sekitar lingkungan ibu dan petugas kesehatan dari Puskesmas Arjasa yang memberikan informasi ASI ekslusif pada kegiatan posyandu.

Penelitian yang dilakukan oleh Firmansyah dan Mahmudah (2012) menunjukkan bahwa sikap ibu berhubungan dengan praktek pemberian ASI. Sikap ibu terhadap pemberian makan bayi menjadi prediktor kuat dalam pemberian ASI eksklusif. (Septian, 2017)

\section{Perilaku Pemberian ASI Eksklusif}

Berdasarkan data yang dikumpulkan, responden yang tidak bekerja maupun tidak bekerja sebagian besar tetap memberikan asi eksklusif. Ibu yang tidak bekerja dapat memberikan ASI eksklusif dikarenakan memiliki waktu yang dihabiskan bersama bayi lebih banyak daripada ibu yang bekerja. Dalam penelitian ini, ibu yang bekerja lebih banyak memberikan ASI eksklusif daripada tidak memberikan ASI ekslusif.
Menurut IDAI (2013), ibu yang bekerja tidak perlu menghentikan pemberian ASI. Penelitian ini sejalan dengan Bahriyah, dkk (2017) bahwa ibu yang bekerja lebih banyak dapat memberikan ASI eksklusif daripada yang tidak. Penelitian yang dilakukan Tsai (2013) menyatakan bahwa ibu yang mendapatkan beban kerja lebih rendah (tidak lebih dari 8 jam sehari) memiliki peluang tetap bisa memberikan ASI hingga 6 bulan sebesar 2,6 kali dan yang diberikan kesempatan istirahat untuk memompa ASI berpeluang 61,6 kali untuk bisa memberikan ASI eksklusif 6 bulan.

Berdasarkan data yang dikumpulkan, diketahui bahwa di wilayah kerja Puskesmas Arjasa dari semua tingkat pendidikan, ibu yang memberikan ASI eksklusif lebih banyak daripada yang tidak memberikan ASI eksklusif. Ibu yang memberikan ASI eksklusif lebih banyak terdapat pada ibu yang menempuh pendidikan lebih rendah yaitu pada jenjang tidak tamat SD, SD, dan SMP. Hal ini sejalan dengan penelitian Bakti (2016) bahwa ibu yang memiliki tingkat pendidikan rendah lebih banyak memberikan ASI eksklusif. Tetapi pada ibu dengan lulusan perguruan tinggi lebih banyak tidak memberikan ASI eksklusif. Ibu dengan pendidikan tinggi lebih dari setengah responden tidak memberikan ASI eksklusif. Hal ini tidak sejalan dengan penelitian Ogunlesi (2009) yang mengungkapkan bahwa ada proporsi yang lebih tinggi pada ibu yang berpendidikan minimal sekolah menengah yang memberikan ASI eksklusif daripada ibu yang berpendidikan lebih rendah. Tetapi hal ini tidak sepenuhnya mutlak mengingat distribusi yang tidak merata pada tiap jenjang pendidikan di wilayah kerja Puskesmas Arjasa. Dari asumsi peneliti, didapatkan bahwa pekerjaan yang dilakukan oleh ibu lulusan perguruan tinggi memiliki jam dan aturan kerja yang lebih tertata dan ketat daripada ibu yang tidak mengenyam pendidikan perguruan tinggi. Sehingga peneliti berasumsi bahwa di wilayah kerja Arjasa bukan pengetahuan dan sikap yang memengaruhi ibu tidak memberikan ASI eksklusif tetapi status ekonomi sosial. Ibu dengan pekerjaan formal sebagian besar tidak dapat memberikan ASI eksklusif sehingga bayi diberi susu formula. Penelitian yang dilakukan Fatmawati (2013) menunjukkan bahwa salah satu faktor yang 
mempengaruhi pemberian ASI secara eksklusif adalah status ekonomi atau penghasilan keluarga.

Berdasarkan lama bekerja dalam sehari, ibu paling banyak bekerja selama 9-12 jam dan dapat memberikan ASI ekslusif yang berasal dari ibu dengan profesi karyawan swasta, karyawan pabrik, dan PNS. Hal ini dikarenakan ibu dapat menerima informasi ASI ekslusif dan dapat menerapkannya, Faktor lain nyang dapat mendukung ibu tetap memberikan ASI ekslusif walaupun jam kerja lebih dari 9 jam adalah dukungan dari orang-orang sekitar ibu seperti suami, keluarga, ibu-ibu lain, dan ajakan Bidan. Tetapi pada ibu yang bekerja selama 5-8 jam dan lebih dari 12 jam sebagian besar tidak dapat memberikan ASI eksklusif. Hal ini terjadi pada ibu yang bekerja sebagai karyawan swasta dan karyawan pabrik dan wiraswasta. Faktoryang dapat mendorong ibu untuk tidak memberikan ASI ekslusif adalah tidak terdapat dukungan orang sekitar seperti tidak adanya kesempatan untuk memerah ASI karena ibu tidak menyempatkan waktu, terpengaruhnya masyarakat sekitar untuk memberikan susu formula dengan berbagai alasan seperti bayi yang diberi susu

\section{DAFTAR PUSTAKA}

Aimi-ASI. (2013). Orang Tua Bekerja pun bisa sukses memberi ASI Ekslusif. https://aimi-asi.org/ layanan/lihat/orang-tua-bekerja-pun-bisasukses-memberi-asi-eksklusif

Badan Pusat Statistiik. (2018). Kecamatan Arjasa dalam Angka 2018. Jember: Badan Pusat Statistik

Bahriyah, F., Putri, M., \& Jaelani, A. K. (2017). Hubungan Pekerjaan Ibu terhadap Pemberian ASI Eksklusif pada Bayi. Journal Endurance, 2(2), 113-118.

Bakti, Imam. (2016). Hubungan Status Pekerjaan, Pendidikan Formal, dan Pengetahuan Ibu dengan Pemberian ASI Eksklusif pada Balita di Posyandu Lestari, Kelurahan Kumpulrejo Kec. Argomulyo, Salatiga. Skripsi. Surakarta: Fakultas Ilmu Kesehatan Universitas Muhammadiyah Surakarta

Balitbang Kemenkes RI. 2013. Riset Kesehatan Dasar; RISKESDAS. Jakarta: Balitbang Kemenkes RI formula tampak lebih gemuk daripada hanya ASI, peningkatan keinginan ibu untuk membeli formula karena ibu-ibu lain memberikan susu formula pada bayinya dan menunjukkan bahwa ibu mampu untuk membeli susu formula, dan lain sebagainya.

Lama waktu bekerja dapat memengaruhi ibu dalam pemberian ASI eksklusif karena semakin lama waktu bekerja semakin lama waktu meninggalkan bayi. Hal ini sejalan dengan penelitian Intami, dkk (2018) yang menyatakan bahwa ibu yang bekerja lebih dari 8 jam sehari dapat memberikan efek kelelahan bagi ibu. Ibu yang lebih lama di tempat kerja, lebih sering meninggalkan bayi sehingga pemberian ASI tidak dilakukan.

\section{KESIMPULAN}

Pengetahuan dan sikap bukan hanya faktor yang memengaruhi pemberian ASI ekslusif, pada wilayah ini status pekerjaan lah yang berperan lebih besar. Pekerjaan tidak dapat dijadikan alasan untuk tidak memberikan ASI eksklusif. Hak dan kesejahteraan ibu telah dijamin dan dilindungi oleh Undang-Undang Kesehatan dan Undang-Undang Ketenagakerjaan.

Dinas Kesehatan Jember (2017). Profil Kesehatan Jember Tahun 2017. Jember: Dinas Kesehatan.

Firmansyah, N., Mahmudah (2012). Pengaruh Karakteristik (Pendidikan, Pekerjaan), Pengetahuan Dan Sikap Ibu Menyusui Terhadap Pemberian Asi Eksklusif Di Kabupaten Tuban. Jurnal Biometrika dan Kependudukan. Vol. 1: 6271

IDAI. (2008). Bedah ASI. Jakarta: Balai Penerbit FKUI Ilhami, Muhammad Fadhil. (2015). Hubungan Tingkat Pengetahuan Ibu Tentang ASI Eksklusif dengan Tindakan Pemberian ASI Eksklusif di Puskesmas Kartasura. Skripsi. Surakarta: Fakultas Kedokteran Universitas Muhammadiyah Surakarta

Intami, E., Zaman, C., \& Kesuma, R. (2018). Analisis faktor yang mempengaruhi pemberian asi eksklusif pada ibu bekerja di sekolah dasar kabupaten banyuasin tahun 2016, 7(01), 86-98. 
Kemenkes RI. (2015). Mari Dukung! Menyusui dan Bekerja. Mari Dukung! Menyusui Dan Bekerja.

Kementerian Kesehatan RI. (2014). Situasi dan Analisis ASI Ekslusif. Jakarta: Infodatin

Mekuria, G., \& Edris, M. (2015). Exclusive breastfeeding and associated factors among mothers in Debre Markos, Northwest Ethiopia: a cross-sectional study. International breastfeeding journal, 10(1), 1. doi:10.1186/s13006-014-0027-0

Ogunlesi TA. (2009). Maternal socio-demographic factors influencing the initiation and exclusivity of breastfeeding in a Nigerian semi-urban setting. Matern Child Health J. 2010;14(3):459465. doi: 10.1007/s10995-008-0440-3

Rahman, N., Dewi, N. U., Fitrasyah, S. I., Bohari, Oktaviani, V., \& Rifai, M. (2017). Factors related to exclusive breastfeeding among mothers in the City of Palu, Central Sulawesi, Indonesia. Malaysian Journal of Nutrition, 23(2), 175-189.

Septiani, Hanulan dkk. (2017). Faktor-faktor yang berhubungan dengan Pemberian ASI Ekslusif Oleh Ibu Menyusui yang Bekerja sebagai Tenaga Kesehatan, Jurnal Ilmu Kesehatan 2(2), 159-174

Sulistiyowati, dan Pulung Siswantara. (2014). Perilaku Ibu Bekerja dalam memberikan ASI Eksklusif di Kelurahan Japanan Wilayah Kerja Puskesmas Kemlagi Mojokerto, Jurnal Promkes 2(1), 89100

Tsai. (2013). Impact of a Breastfeeding-Friendly Workplace on an Employed Mother's Intention to Continue Breastfeeding After Returning to Work. Breastfeeding Medicine Journal 8(2) 